\title{
Protectores VS Depredadores. Cartografía y visualización de la biopiratería de las medicinas tradicionales en Twitter
}

\author{
Protetores VS Predadores. Mapeando e visualizando a biopirataria de medicamentos tradicionais no Twitter \\ Protectors VS Predators. Mapping and visualizing biopiracy of traditional medicines on Twitter
}

Luis Torres-Yepez

Université Paris 8 Vincennes-Saint Denis, Francia

DOI: https://doi.org/10.18472/cvt.21n1.2021.1922

luisyepez13@gmail.com

Redalyc: http://www.redalyc.org/articulo.oa?

id $=115466307007$

\author{
Khaldoun Zreik \\ Université Paris 8 Vincennes-Saint Denis, Francia \\ zreik@univ-paris8.fr
}

Recepción: 16 Marzo 2020

Aprobación: 25 Marzo 2021

\section{ReSUMEN:}

La biopiratería es una problemática que se refiere a la apropiación de la propiedad intelectual de los conocimientos tradicionales y la biodiversidad. En esta investigación se propone desarrollar la visualización y la cartografía de la biopiratería de las medicinas tradicionales en la red social Twitter utilizando los métodos digitales. De esta manera, se presentan una serie de gráficos donde se identifican los territorios de los actores y las plantas medicinales que son mencionados en los tweets. Se concluye que los métodos digitales y la visualización de datos nos permiten analizar las problemáticas del fenómeno e identificar ciertas plantas medicinales relacionadas con conocimientos ancestrales que en el contexto del patrimonio cultural inmaterial pueden estar amenazadas.

Palabras ClaVE: biopiratería, patrimonio cultural inmaterial, medicinas tradicionales, plantas medicinales, cartografía de internet, métodos digitales, visualización de datos, humanidades digitales.

\section{Resumo:}

A biopirataria é uma problemática que se refere a apropriação da propriedade intelectual dos conhecimentos tradicionais e da biodiversidade. Esta pesquisa se propõe a desenvolver uma visualização e uma cartografia da biopirataria das medicinas tradicionais na rede social Twitter, utilizando os métodos digitais. Assim serão apresentados uma série de gráficos aonde se identificam os territórios dos atores e das plantas medicinais mencionados nos tweets. Concluímos assim que os métodos digitais e a visualização de dados nos permitem analisar a problemática do fenômeno e identificar que certas plantas medicinais relacionadas a conhecimentos ancestrais podem estar ameaçadas dentro do contexto do patrimônio cultural immaterial.

Palavras-CHave: biopirataria, patrimônio cultural imaterial, medicamentos tradicionais, plantas medicinais, mapeamento da internet, métodos digitais, visualização de dados, humanidades digitais.

\section{Abstract:}

Biopiracy is a problem that refers to the appropriation of the intellectual property of traditional knowledge and biodiversity. In this research it is proposed to develop the visualization and mapping of the biopiracy of traditional medicines in the social network Twitter using digital methods. In this way, a series of graphs are presented where the territories of the actors and the medicinal plants that are mentioned in the tweets are identified. It is concluded that digital methods and data visualization allow us to analyze the problems of the phenomenon and identify certain medicinal plants related to ancestral knowledge that in the context of intangible cultural heritage may be threatened.

KEYWORDS: biopiracy, intangible cultural heritage, traditional medicines, medicinal plants, internet mapping, digital methods, data visualization, digital humanities. 


\section{INTRODUCCIÓN}

Se considera que el término biopiratería es un concepto contemporáneo ya que se comienza a utilizar en el año 1994 por la organización etcGroup (antes llamada RAFI) (RAFI, 1994), pero también se encuentra que en términos de apropiación cultural, la biopiratería es una práctica antigua con orígenes colonialistas (Boumediene, 2016; Shiva, 1997). Aubertin y Moretti (2013) mencionan sobre el término biopiratería.

La Coalición contra la biopiratería (etcGroup) define la biopiratería como la apropiación general mediante los derechos intelectuales de recursos genéticos, de conocimientos locales y de culturas tradicionales pertenecientes a campesinos o comunidades indigenas quienes han desarrollado y mejorado el uso de recursos naturales. La biopiratería incluye la bioprospección, las patentes sobre genes y moléculas y la comercialización de los conocimientos culturales (Aubertin \& Moretti, 2013, p. 91).

$\mathrm{Al}$ mismo tiempo que surge el término biopiratería, emerge un movimiento que busca la legitimación y la protección de los conocimientos tradicionales, locales e indigenas. De hecho, la principal problemática de la biopiratería se encuentra en la falta de legitimación y valoración de los conocimientos tradicionales por parte de gobiernos e instituciones tanto a nivel local como internacional. Como consecuencia, la problemática se extiende a la apropiación de conocimientos y recursos biológicos por parte de empresas e instituciones con la ayuda de otras instituciones que gestionan los derechos de autor y la propiedad intelectual (OMPI). Podemos encontrar diversos casos de biopiratería relacionados con plantas medicinales como por ejemplo: el caso del Neem y la Curcuma en la India, la Ayahuasca, la Quinoa, la Maca y la Mayacoba en America Latina y la Hoodia y la Rooibos en Africa (Aubertin, Pinton, \& Boisvert, 2007; Delgado, 2002; Dumesnil, 2012; IEPI, 2016).

El caso de la biopiratería de los conocimientos alrededor de las medicinas tradicionales ha sido ignorado por gobiernos, instituciones y empresas por mucho tiempo, los casos de biopiratería como muestra el etcGroup (RAFI, 1994) son variados a lo largo del tiempo. En la actualidad por fin se encuentran discusiones sobre el tema en instituciones como la Organización Mundial de la Propiedad Intelectual (OMPI)[1] y por otro lado en el Convenio sobre la Diversidad Biológica[2] y el protocolo de Nagoya (Convention Sur La Diversité Biologique [CBD], 2012). De la misma forma, la Organización de las Naciones Unidas para la Educación, la Ciencia y la Cultura (UNESCO) menciona en el contexto del patrimonio cultural inmaterial (PCI), que las tradiciones y los conocimientos medicinales de los Kallawaya, en Perú, han sido afectados por la falta de protección jurídica frente a las empresas farmacéuticas[3]. La UNESCO tiene pocos casos que tratan sobre las medicinas tradicionales en su lista sobre el PCI, por lo cual, pensamos que es importante un rol más activo de la UNESCO en la protección de los conocimientos locales y las medicinas tradicionales como Patrimonio Cultural Inmaterial frente a la biopiratería (UNESCO, 2003). Al mismo tiempo las medicinas tradicionales en su conjunto, es decir los conocimientos y las plantas medicinales, no entran totalmente en la categoría de PCI, por lo cual es necesario proponer otros términos o categorías para protegerlos en su conjunto. En este sentido Burelli (2004) propone el término patrimonio ethno-environnemental (en español etnoambiental), para proteger los conocimientos tradicionales relacionados con la biodiversidad en el contexto de los derechos de autor.

La visualización de datos y la cartografía de Internet permiten analizar las publicaciones y conversaciones entre los usuarios, sus comportamientos, las tendencias y asimismo observar las comunidades y las relaciones entre los actores (Bastard, et al., 2017; Diminescu, 2012; Severo \& Venturini, 2016). Nos interesa el análisis y la cartografía de la red social Twitter, ya que es una red social abierta donde se encuentran publicaciones sobre fenómenos sociales y políticos. Diversas investigaciones se han desarrollado en el contexto de los métodos digitales sobre Twitter, podemos mencionar entre otras la herramienta DMI-TCAT[4] (Borra \& Rieder, 2014), la cual permite la colecta y el análisis de la información difundida en Twitter.

El objetivo de esta investigación exploratoria es colectar las publicaciones en Twitter y desarrollar el análisis y la cartografía de las conversaciones alrededor de la biopiratería de las medicinas tradicionales. Las 
preguntas que buscamos responder en este artículo son las siguientes: ¿Qué organizaciones, empresas, medias, investigadores y activistas podemos encontrar en las discusiones en Twitter alrededor de la biopiratería de las MT? ¿Qué plantas medicinales podemos encontrar en las conversaciones alrededor de la biopiratería? ¿Qué aportación podemos hacer del análisis de la biopiratería de las MT en Twitter en el contexto del PCI?. Por lo tanto, tomando como base las aportaciones de los métodos digitales desarrollamos el análisis del fenómeno de la biopiratería en Twitter presentando diversos gráficos y la cartografía de las plantas medicinales que son mencionadas en las conversaciones.

\section{MÉtodos digitales}

Los llamados métodos digitales son una serie de métodos, técnicas y herramientas que permiten realizar investigaciones sobre la redes sociales e Internet en general (Diminescu, 2012; Rieder, 2013; Rogers, 2013; Severo \& Venturini, 2015). En el dominio de lo métodos digitales se propone desarrollar herramientas con el objetivo de explorar y analizar los objetos digitales: hipervínculos, me gusta (likes), palabras claves (tags), sellos de fecha (datestamps), es decir, se refieren a los "metadatos" que guardan las empresas Social Media en sus bases de datos sobre la información de los perfiles personales y las actividades de los usuarios (Rogers, 2019). Proponen que con la colecta y el análisis de esos datos es posible responder preguntas de investigación sobre fenómenos socioculturales.

El método de análisis que hemos diseñado en esta investigación se desarrolló a partir del gráfico siguiente:

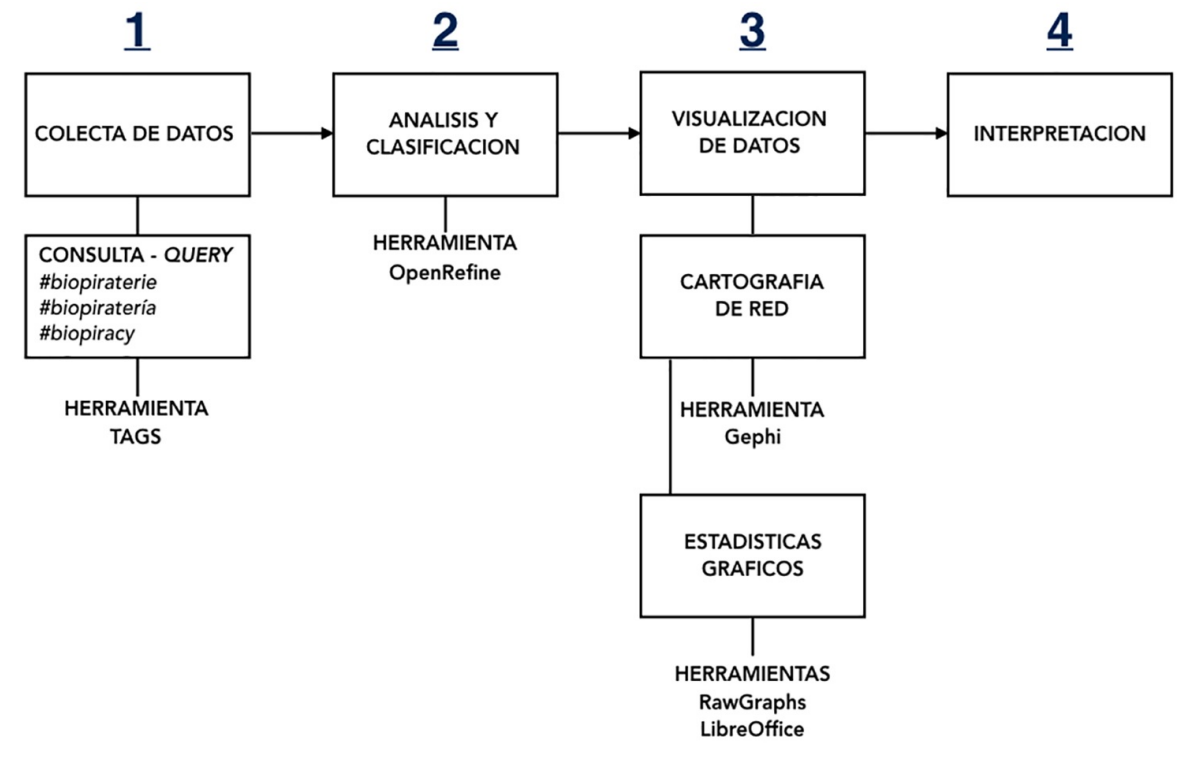

FIGURA 1

Método de investigación

autores

El método se desarrolló en cuatro etapas: la extracción o la colecta de datos, el análisis y la clasificación, la visualización y finalmente la interpretación.

1. En la primera etapa, la extracción de datos en Twitter se realizó mediante la herramienta TAGS [5] buscando la palabra biopiratería en tres idiomás diferentes, en español, inglés y francés, por lo cual lanzamos la consulta siguiente: biopiracy OR biopiraterie OR biopiratería OR bio-pirateria OR bio-piracy OR biopiraterie.

2. En la segunda etapa, con la herramienta OpenRefine [6] se desarrolló el análisis, la clasificación y la limpieza general de la base de datos (DB) colectada en TAGS. Con el objetivo de analizar todos los tweets 
registrados se decidió desarrollar la cartografía de red a partir de la relación entre los usuarios y los tweets. Para el tratamiento y el análisis de los tweets se realizó un agrupamiento (clustering) de los textos, por lo cual se agrupo en una misma categoría una publicación normal y un RT, así como otras con ciertas variaciones en el texto (Fig. 2). Asimismo se analizaron los textos de los tweets para encontrar rastros (traces[7]) sobre organizaciones, activistas, empresas y plantas medicinales o productos relacionados con las MT y se creo una nueva variable en la BD para añadir el nombre de la entidad o de la planta.

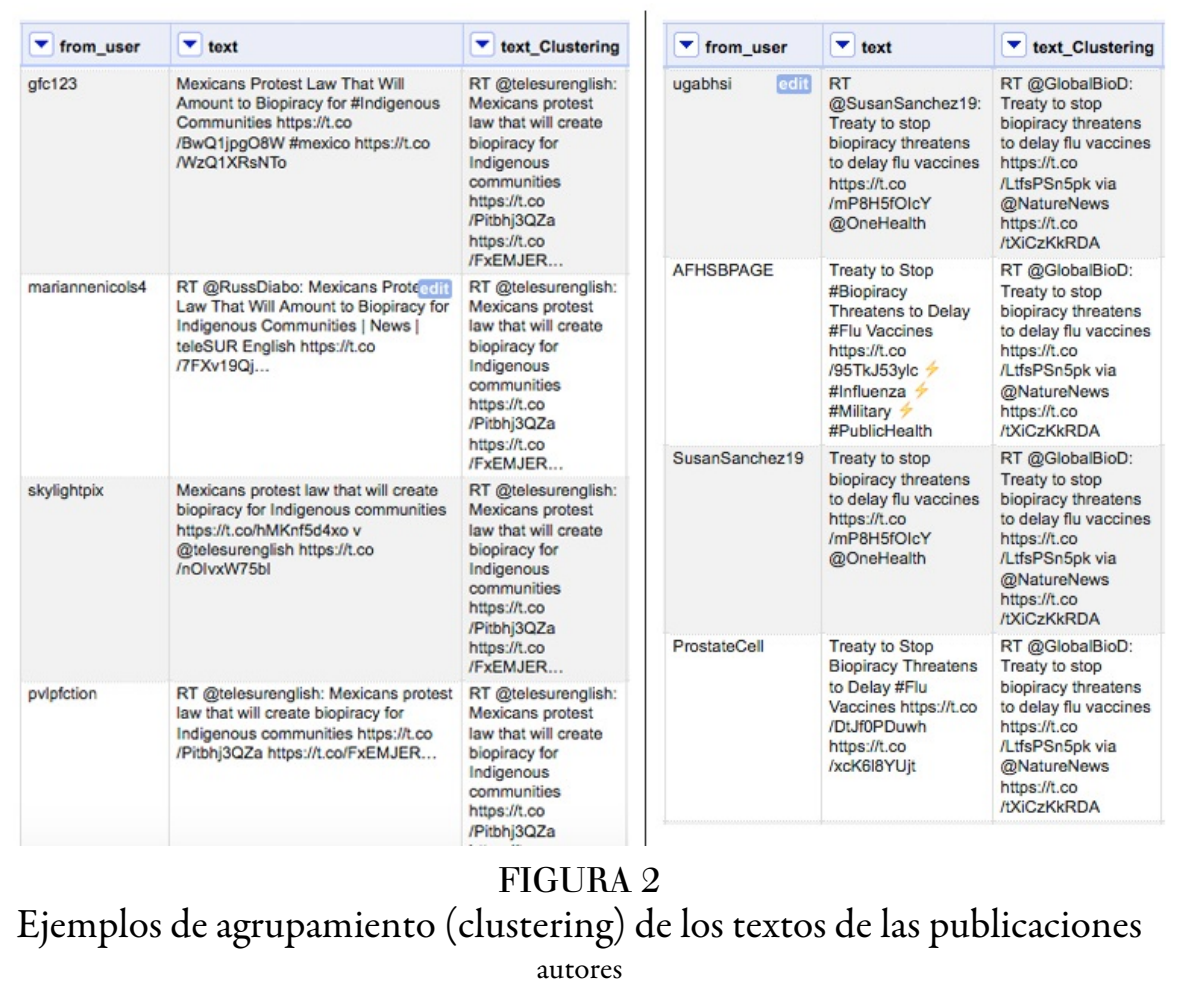

3. Teniendo limpia y organizada la base de datos, en esta etapa se realizó el modelado de dos bases de datos, una de nodos y otra de relaciones, para realizar posteriormente el análisis de redes. En Gephi[8] se desarrolló el análisis utilizando el algoritmo Force Atlas para visualizar la red espacialmente y se aplicaron los valores in-degre y out-degre para identificar los nodos con mayor y menor interacción. En esta fase también se exportaron las bases de datos para realizar gráficos estadísticos de los datos.

4. En la etapa de la interpretación, se realizó el diseño visual de la cartografía utilizando también otras herramientas de representación de datos.

\section{VisUALIZACIÓN Y CARTOGRAFÍA DE LOS TERRITORIOS DE LA BIOPIRATERÍA DE LAS MT}

Como resultado de la colecta de datos en Twitter entre las fechas 06/02/2017 - 06/10/2017 obtuvimos una muestra de 3,995 publicaciones (Tweets) de los cuales se encontraron 494 repetidos y 1 con error, por lo cual se realizó el análisis con una muestra total de 3,500 Tweets.

Asimismo se encontraron 581 tweets sin hashtags ni marcas de usuarios mencionados (@usuario). 


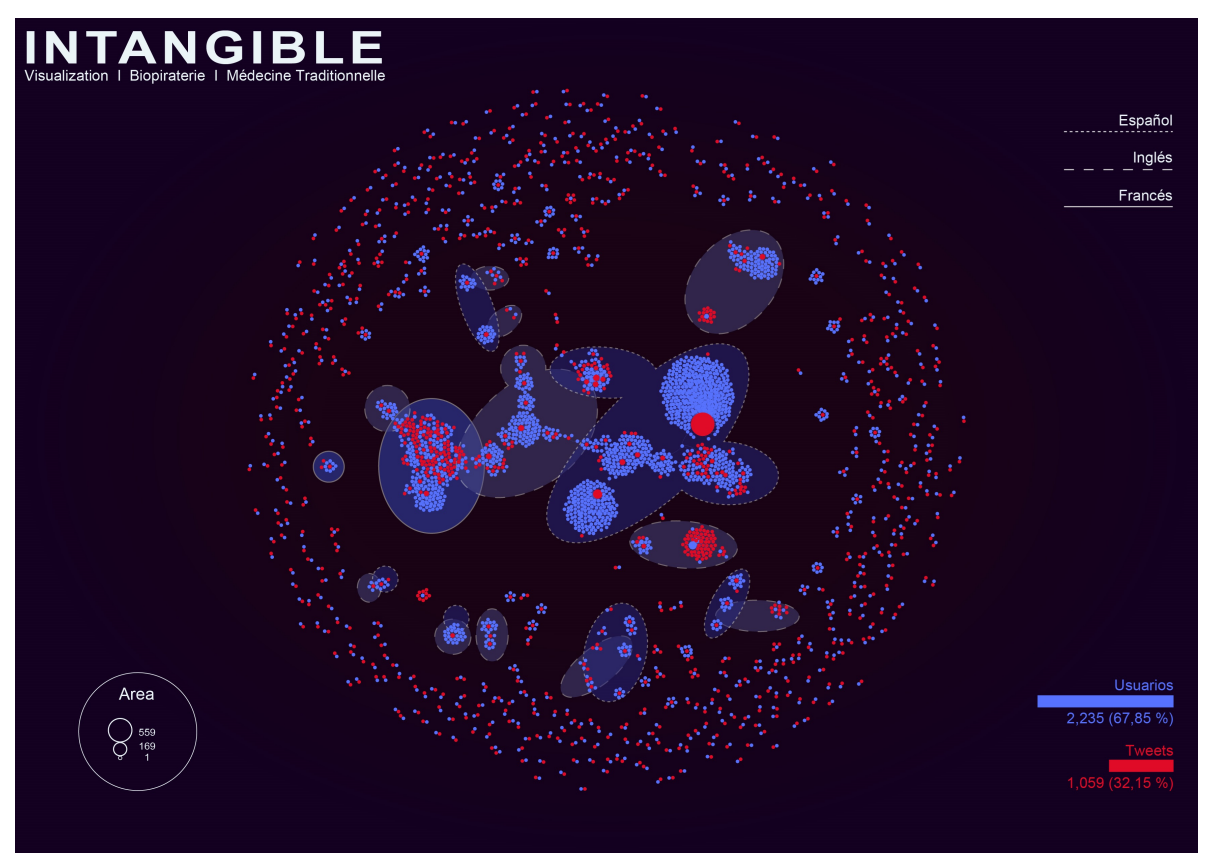

FIGURA 3

Cartografía general del análisis entre usuarios y tweets autores

En la figura. 3 se presenta una cartografía inicial donde se identificaron por un lado los usuarios y tweets, y por otro lado, los territorios de los tres idiomas principales de los usuarios (español, inglés y francés). A partir del clustering realizado en la etapa anterior se puede observar que de los 3500 tweets iniciales se desarrollo la cartografía de redes entre 2,235 usuarios y 1059 tweets. La diferencia se explica por un lado, por el agrupamiento de textos y por el otro, se encontraron usuarios que enviaban el mismo tweet más de una vez. En la cartografía se observa en la periferia la publicación de muchos tweets con pocas interacciones y algunos casos de publicaciones solitarias. En esta investigación hemos observado la importancia de los usuarios y tweets de la periferia, ya que como veremos más adelante muchos de ellos tienen menciones a temas de interés, $\mathrm{y}$ a instituciones, organizaciones y activistas. 


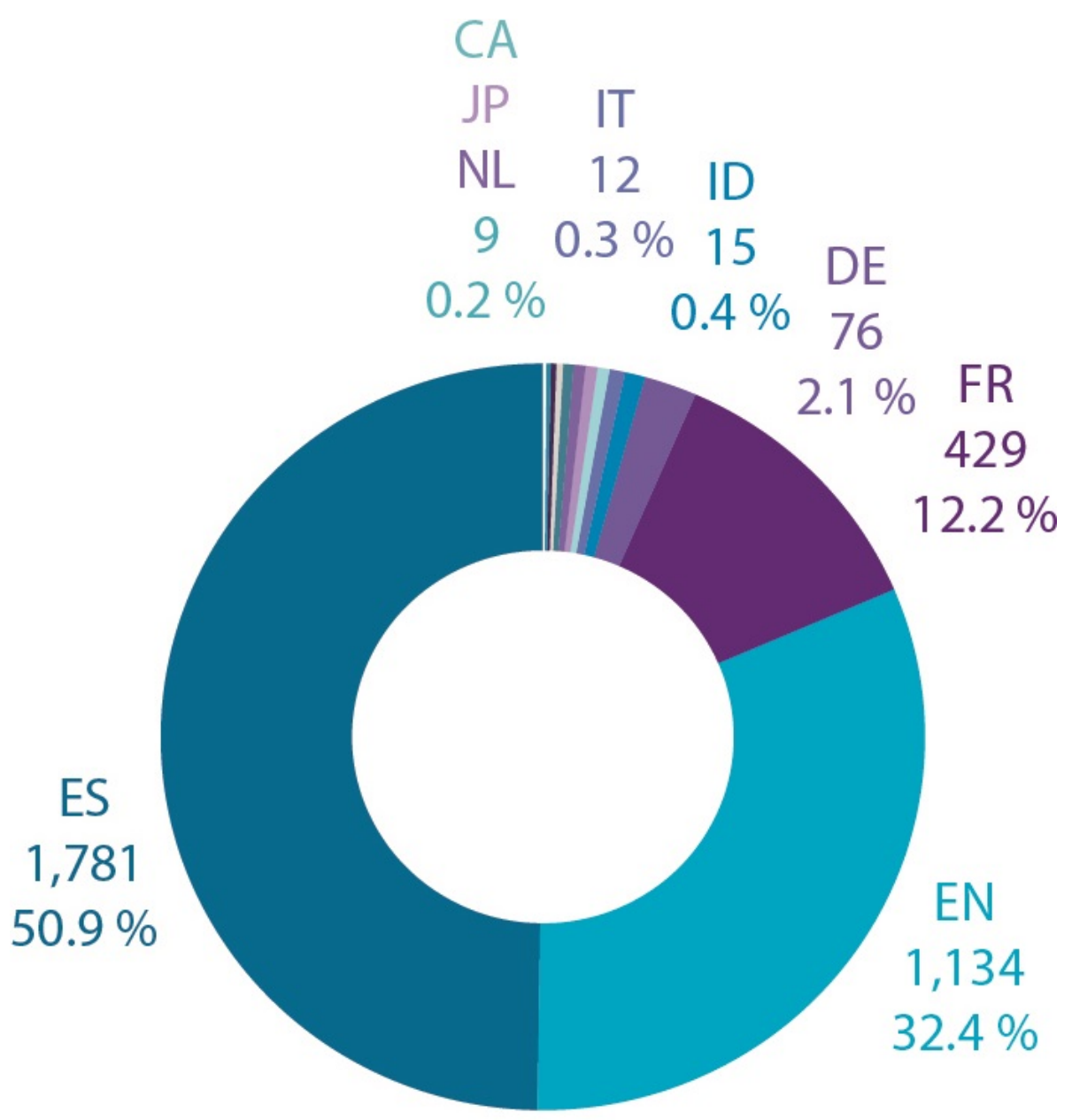

FIGURA 4

Idioma de los usuarios

autores

En una primera etapa pudimos observar en la base de datos que el idioma de origen de los usuarios era variado (Fig. 4), aunque las publicaciones principalmente fueron realizadas en inglés, francés y español. En el territorio más grande o principal, se pueden observar a la izquierda el territorio francés, al centro el territorio inglés, el cual sirve de puente al territorio español, y en donde encontramos unicamente contenidos de origen latinoamericano. En tanto, en el territorio francés se puede observar una mayor cantidad de tweets, lo que representa una mayor interacción entre los usuarios.

\subsection{Los tweets mas difundidos}

Siguiendo con la fase de visualización y cartografía se presenta en la Figura. 5 los 20 tweets más difundidos. 


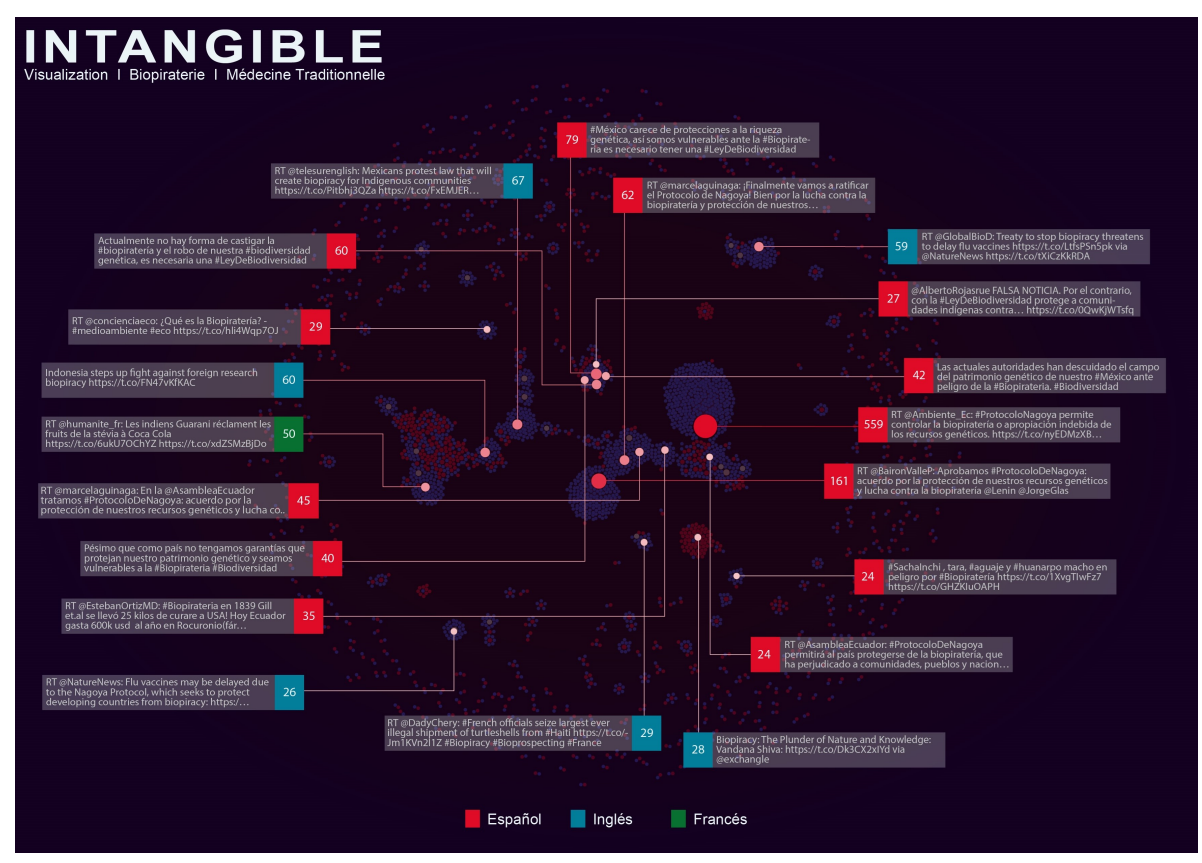

FIGURA 5

Cartografía de los tweets más difundidos

autores

En la figura 4 se presenta una red donde se aplicó la variable in degree para darle más relevancia a los tweets. El número indica la cantidad de veces que el tweet es mencionado en la red. De manera práctica utilizaremos ese número como referencia para explicar de manera con más detalle cada uno. Los tweets 559 y 161 son difundidos principalmente por bots y hablan sobre la implementación del protocolo de Nagoya en Ecuador, así como también los tweets 62, 45 y 24 que forman parte de la misma campaña de difusión. El Tweet más difundido en inglés (67), se refiere a un artículo de Telesur[9] (canal de televisión y medias venezolano), el cual menciona las protestas contra la \#LeyDeBiodiversidad en México, que se relaciona con la ratificación del protocolo de Nagoya $(79,60,42,40,27)$. Se observa en este caso una disputa entre los ciudadanos y organizaciones que están en contra de la ley y los bots que posiblemente son lanzados por el gobierno para contrarrestar el movimiento contra la ley de la biodiversidad. El movimiento activista pide suspender la ley de la biodiversidad y demanda abrir el proceso y realizar una consulta ciudadana donde participen los grupos indigenas, quienes son los principales afectados, ya que la ley, consideran, permitirá la privatización de los recursos genéticos y los conocimientos tradicionales sin consultar a las comunidades indigenas. Esta contradicción es importante de resaltar, ya que es una problemática consecuencia del alto grado de corrupción en las instituciones mexicanas. Los tweets 26 y 59 mencionan un artículo publicado en la revista@NatureNews sobre los riesgos del protocolo de Nagoya para el desarrollo de la vacuna contra la influenza $(\mathrm{flu})$. El tweet 28 menciona un libro de Vandana Shiva quién es una activista reconocida contra la biopiratería. Se observa asimismo el tweet 60 que hace mención a la biopiratería en Indonesia, y el cual tiene como origen un artículo del periódico The Jakarta Post, el cual se refiere a la implementación del protocolo de Nagoya y al control de visas a investigadores interesados en la biodiversidad de la región. En otro tweet, en Haiti (29 inglés), se menciona un artículo del periódico NationNews que se refiere al trafico de 380 caparazones de tortuga detenidos en el aeropuerto Charles de Gaulle en Francia. El tweet 29, pero en español, cita la revista digital "Conciencia Eco" donde se responde la pregunta ¿qué es la biopiratería?. Asimismo, se observan tres tweets importantes los cuales mencionan algunas plantas medicinales en riesgo de biopiratería como son, la Estevia (50), la Sacha inchi, Tara, Aguaje y Huanarpo macho (24) y por otro lado el tweet 35, que hace referencia a la biopiratería del curare, que es un extracto vegetal de origen amazónico, 
creado por el grupo indígena Jivaros y resultado de una mezcla de plantas, el cual es de uso común como anestésico. El tweet 50 sobre la Estevia, menciona un artículo del periódico francés l'Humanité[10], sobre la emergencia de un movimiento de activistas (principalmente en Europa) quienes lanzaron una campaña en línea (280,000 firmás) para exigir a Coca-cola que comparta los beneficios del uso de la Estevia con los indios Guaranís, quiénes utilizan esta planta en sus tradiciones y rituales. Sobre el tweet 24, se menciona un artículo del periódico LaRepublica[11] de Perú, donde se evoca la solicitud de revocación de una patente China relacionada con la Sacha Inchi, y hace mención también al peligro de biopiratería de otras plantas de origen peruano.

\subsection{Los territorios de los manifestantes, depredadores y protectores}

Continuando con el análisis de los resultados, a continuación se presenta la cartografía de los territorios de los dos bandos (fig. 6), es decir, por un lado los llamados aquí "protectores": las organizaciones, empresas y activistas quienes buscan proteger los conocimientos tradicionales y la biodiversidad; por otro lado, los llamados "depredadores" (los acusados de biopiratería), los que se apropian, se aprovechan y/o comercializan los recursos naturales y los conocimientos tradicionales. Por tanto, aquí presentamos la cartografía de los protectores, los depredadores y los manifestantes.

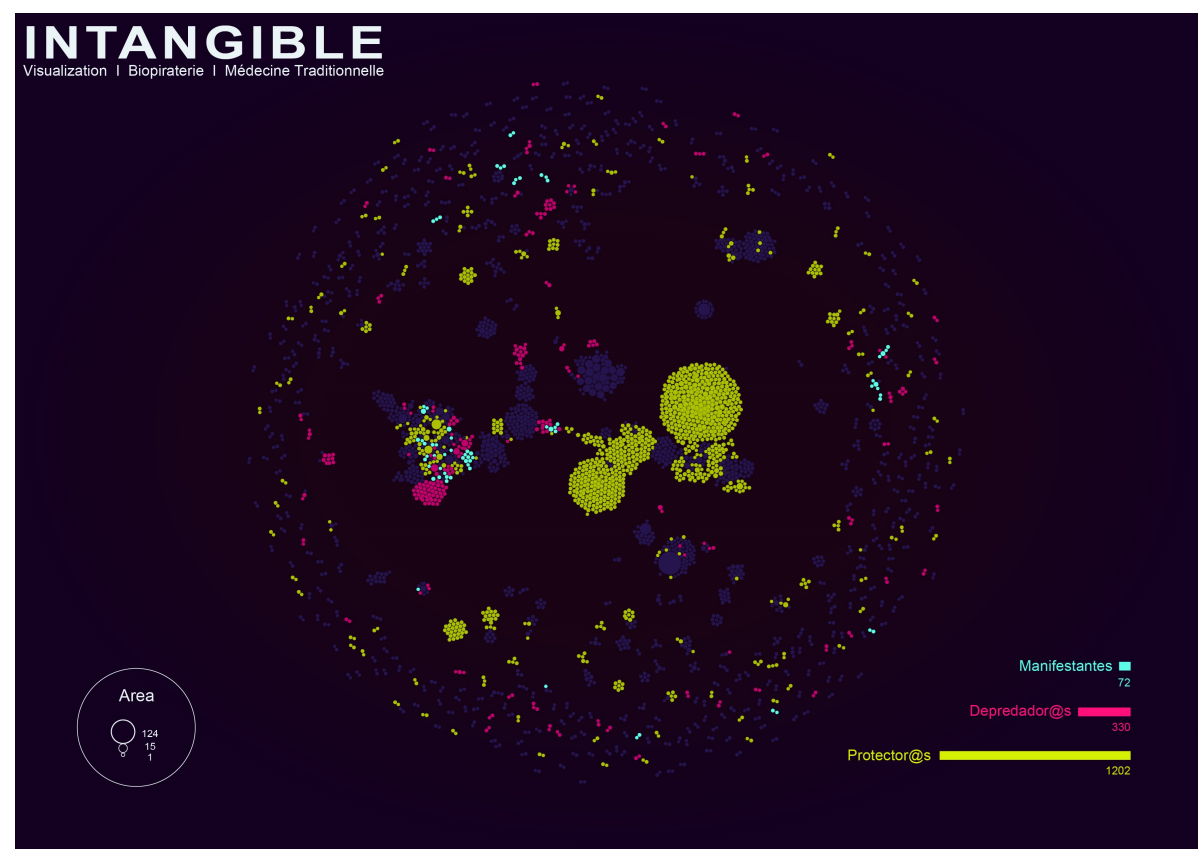

FIGURA 6

Los territorios de los manifestantes, protectores y depredadores

autores

Se desarrolló esta cartografía, primero analizando los contenidos de los tweets, y después se clasificaron los contenidos según los actores que son mencionados creando dos variables en la base de datos. Cruzando las dos variables, protectores y depredadores fue posible definir a los manifestantes, por lo tanto, en el territorio de los manifestantes se encuentran tweets donde se mencionan en los textos tanto a depredadores como a protectores. Podemos observar claramente que el territorio de los protectores es mayor al territorio de depredadores.

Mediante esta cartografía (fig. 6) explicaremos principalmente que sucede y quienes son los manifestantes, y en la siguientes secciones del artículo presentaremos de manera mas específica quienes son los depredadores y los protectores. 
En el territorio francés (izquierda) se observan la mayor cantidad de manifestantes, luego al centro del gran continente encontramos otros que se manifiestan en inglés. En estas regiones se encontró que se difundieron los siguientes tweets:

RT@Francelibertes: \#Biopiraterie. Les Guarani réclament les fruits de la stévia à @cocacolafr https:// t.co/Ayaz0EVaXY https://t.co/pv8saPy...

RT@lgsalcede: Biopiraterie et multinationales : @Francelibertes souhaite que Coca Cola partage ses bénéfices avec les Indiens https://t.co...

\#CocaCola Urged to End \#Biopiracy Against \#INDIGENOUS \#Guarani \#paraguay \#benefitsharing @CBDNews@PublicEyeSuisse... https://t.co/dBeK0I2dWD

En estos tres tweets (que también se encuentran en la periferia), se menciona la biopiratería de la Estevia por la empresa coca-cola, quién según la organización PublicEye, ha registrado múltiples patentes sobre la Estevia, la cual es una planta que forma parte de los conocimientos tradicionales de los Guaraníes en America del Sur (Paraguay y Brasil). Se encuentran diversas organizaciones involucradas (International Stevia council (ISC)), pero quienes sobresalen en Twitter son France Libertés y PublicEye quienes en conjunto lanzaron una convocatoria[12] [13] con más de 260,000 firmas, para demandar principalmente a Coca-cola (aunque también mencionan a otras empresas como Nestle y Cargill), que comparta los beneficios que deriven de la comercialización de la Estevia, como lo menciona el protocolo de Nagoya.

Asimismo, se encontraron otros tweets en el territorio francés que se refieren también a problemáticas que mencionan plantas medicinales, como el caso de la Quassia Amara y la controversia con el laboratorio de investigación francés Institut de Recherche pour le Developpement (IRD):

RT@emmanuelpoilane: Cas de \#biopiraterie Quassia Amara : la défense laborieuse de l'@ird_fr,par @Francelibertesvia@MediapartLeClub htt...

Quand@Tburelli pour@Francelibertes et l' @ird_fr discute de \#biopiraterie pour @infogm https:// t.co/o5AVuz4rUL

La Quassia Amara, es una planta que tiene propiedades particulares para tratar el paludismo, por lo cual el IRD registró una patente sobre la extracción de la molécula para tratar la enfermedad. El primer tweet tiene como origen un artículo publicado en el periódico francés MediaPart[14], donde se contraponen, por un lado, el punto de vista del IRD y por otro lado, el de FranceLibertés y Thomas Burelli (profesor de derecho en la universidad de Ottawa). En el artículo se hace mención a la falta de un marco legal para proteger por un lado a los conocimientos tradicionales y por otro a los recursos genéticos. Es decir, se menciona que es el estado o el país quien debería controlar el acceso a los recursos genéticos y por otro lado es la comunidad indígena quien tendría que proteger sus conocimientos sobre el uso de la Quassia Amara. Por lo tanto, el IRD se escuda en este conflicto para protegerse de la acusación de biopiratería. El principal argumento para acusar al IRD de biopiratería es que en ese momento no existió la intensión por parte del IRD de reconocer los conocimientos tradicionales como fuente de información y por lo tanto no respetar el protocolo de Nagoya sobre el acceso a recursos genéticos y participación en los beneficios.

El segundo tweet menciona la publicación de una discusión en el sitio Internet de la organización InfoGM[15] entre dos actores que representan a cada bando, por un lado Thomas Burelli y por el otro Catherine Aubertin (Investigadora del IRD). En este artículo, a diferencia del anterior, ya se menciona el compromiso por parte del IRD a cumplir con el protocolo de Nagoya a partir de una reunión entre la comunidad indígena y Thierry Mandon (secretario del estado francés encargado de la enseñanza y de la investigación superior). Asimismo, se mencionan también las dificultades para definir los roles en el marco legal sobre el control de los recursos y los conocimientos tradicionales en el marco del protocolo de Nagoya. Problemática que también se observo en el caso de México y la \#LeyDeBiodiversidad (fig. 5).

Por otro lado, encontramos otro tweet entre los manifestantes franceses, el cual cita un artículo titulado DivSeek : chronique d'une biopiraterie Legal (Biopiratería: crónica de una biopiratería legal) publicado en el sitio de la organización InfoGM[16]. 
@Divseek : la biopiraterie légalisée? \#semence https://t.co/Wndb1PUe1o @viacampesinaFR @FAOnews \#TIRPAA@biopiraterie @ccfd_tsolidaire

En este artículo se mencionan los riesgos de concentrar la gestión de bases de datos de información de semillas, así como secuencias genéticas en la organización publica/privada llamada DivSeek[17]. El objetivo de DivSeek es desarrollar un sistema estandarizado global de bases de datos (Digital Object Identifiers), para identificar el contexto particular de cada semilla o recurso genético en el mundo. Entre las dificultades que menciona el artículo sobre el tema de la gestión de la información que pretende desarrollar DivSeek, se menciona por un lado, el origen del financiamiento del proyecto, ya que algunos provienen de empresas privadas como DuPont y Syngenta, y por otro lado, la gestión de la propiedad intelectual y la participación de los beneficios, por ejemplo, el rol de Vía Campesina y sus afiliados en ese contexto.

En el tweet mencionado, se citan una serie de organizaciones quienes se encuentran de alguna forma involucradas en la problemática que trata el artículo. Se encuentra que Vía Campesina[18] es una de las entidades mencionadas, la cual es una organización formada por más de 182 organizaciones que se encuentran en 181 países. La FAO (Food and Agriculture Organization of the United Nations), que es una parte de la ONU y quien busca organizar a otras instancias y estados para luchar contra el hambre en el mundo. Asimismo, se encuentra \#TIRPAA, en español TRFAA (Tratado internacional sobre los recursos Fitogenéticos para la Alimentación y la Agricultura), conocido como tratado internacional de semillas. El TRFAA es un tratado que surge en el contexto del Convenio sobre la Diversidad Biológica (CBD) y que busca garantizar el acceso y la seguridad alimentaria en materia de los recursos filogenéticos y la agricultura. También se menciona a la organización CCFD Terre Solidaire[19] (Comité Catholique contre la Faim et pour le Développement), quien se encuentra en 70 países (según su sitio web) y promueve una repartición justa de los recursos para luchar contra el hambre y la desigualdad.

Se encuentra asimismo otros tweet en la periferia del lado derecho, de los cuales algunos se refieren al movimiento para proteger a los guaranies y la Estevia, y otros hacen referencia a un artículo publicado en el sitio de la organización ETCGroup[20]:

RT@ETC_Group: "Congrats" @CocaCola, @ClarinsNews, @DivSeek, @Canada @blairomaggi on your Captain Hook Biopiracy Awards \#cbd \#COP13 https:/...

El tweet se refiere al artículo que lleva por título The Captain Hook Awards reveal 'biopirate' villains and celebrate biodiversity defenders at UN Biodiversity Convention. El artículo evoca la manifestación organizada por la Coalición contra la biopiratería (Coalition Against Biopiracy (CAB)) que se realizó durante la conferencia de la COP13 en 2016. A la par del evento internacional COP13 se nombraron los ganadores de los premios a los biopiratas del año The Captain Hook Awards. Entre los ganadores se encuentran DivSeek, que ya conocemos, el gobierno de Canada, por financiar y permitir la digitalización de muestras de recursos genéticos sin tomar en cuenta las implicaciones y riesgos de biopiratería. Se menciona también entre los ganadores al político brasileño Blairo Maggi, quien era secretario de agricultura de Brasil, y a quien se le dio un premio por no ratificar el protocolo de Nagoya, y apoyar un marco legal que permite la biopiratería en Brasil. Coca-cola recibió el premio al "biopirata más codicioso" por la acusación de biopiratería en el tema de la Estevia. Asimismo, la empresa de cosméticos Clarins también recibió el mismo premio, acusada por un lado de usar y patentar los conocimiento tradicionales africanos alrededor del árbol Harungana y por otro lado, por vender el kilo del ingrediente activo en 7 mil dólares y pagar a los recolectores africanos 2 dólares por un kilo de hojas secas. En tanto, hubo dos premios a organizaciones protectoras contra la biopiratería, uno fue el premio a la "defensa legal mas creativa" que se concedió al Consejo Regional Indígena Maya de Bacalar[21] por la defensa de sus tierras y detener la siembra de soya transgénica. De la misma forma, se dio el premio a la "mejor defensa de un pueblo" al Tribunal Permanente de los Pueblos México[22], por lograr la prohibición del maíz transgénico en México. Se observa por lo tanto, múltiples y diversos actores que son mencionados directamente en el tweet y otros en el artículo. Sobre la prohibición del maíz transgénico en México, podemos observar que la lucha sigue aún en estas fechas, como se menciona en 
noticias actuales, ha sido apenas a finales del 2020[23] cuando se ha prohibido el maíz transgénico en México, donde el proceso de autosuficiencia en la producción del maíz apenas empieza.

Por último, se encuentra un tweet en la periferia del lado derecho, escrito en alemán y que cita al documental Seed: the untold story[24], donde se menciona a la activista de origen indio Vandana Shiva en su lucha contra Monsanto.

@drvandanashiva@Seed_TheMovie 2014 Europa. Patentamt unterstützt Biopiraterie von Monsanto Patent auf Nutzung d... https://t.co/GmYmZTQLPU

En el sitio Internet del documental se puede observar los múltiples premios que ha ganado y el impacto que ha tenido para informar, por un lado del impacto negativo de los OGM y los pesticidas en el ser humano y la biodiversidad, y por otro lado, informar sobre el control que tienen empresas como Syngenta, Bayer y Monsanto en el mercado mundial de producción y comercialización de semillas genéticamente modificadas (OGM).

El análisis que podemos hacer de la cartografía de los manifestantes, nos permite tener un conocimiento mas profundo del contexto actual de la biopiratería en el mundo.

\subsection{Depredadores VS protectores}

A continuación se presentan dos gráficos donde se observan los protectores y los depredadores (los acusados de biopiratería). Para desarrollar la identificación de las diferentes entidades en los tweets, se realizó un análisis cualitativo de los textos publicados, para identificar los rastros textuales que nos indicaran la presencia de organizaciones, empresas, activistas y laboratorios de investigación. Por lo tanto se presentan en una misma figura la cartografía de los dos tipos de actores que se identificaron. 


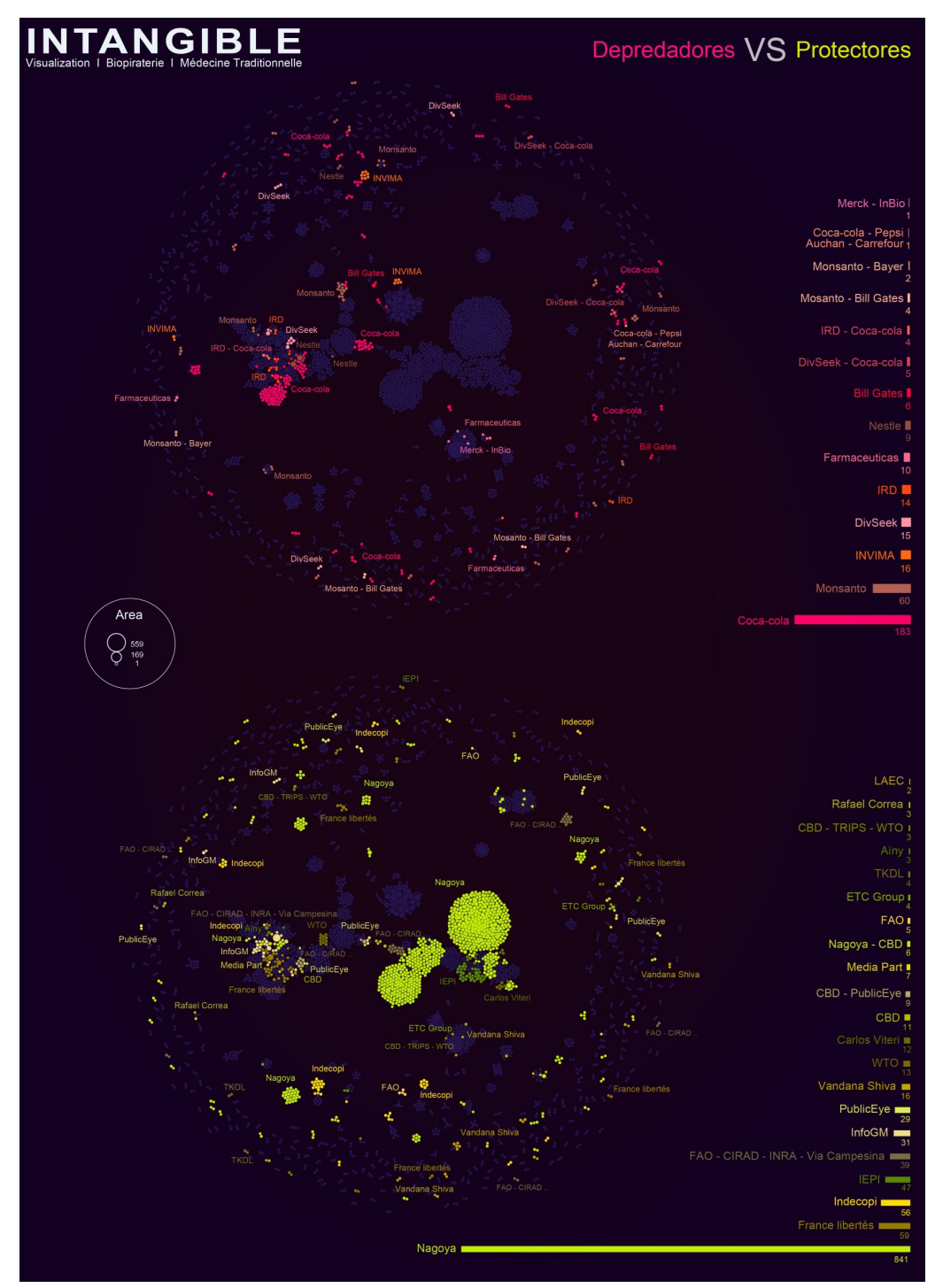

FIGURA 7

Los territorios de los protectores y depredadores

autores

Se observa en la cartografía de la fig. 7 que los depredadores se encuentran principalmente mencionados en el territorio francés, ingles y en la periferia. Por otro lado, los protectores se observa que son cuantitativamente más citados en el territorio latinoamericano, donde principalmente se identifica el protocolo de Nagoya, tal como también lo explicamos en la fig. 5 .

Entre los depredadores podemos observar a Coca-cola en primer lugar, que como ya vimos en el capítulo anterior, se encuentra involucrada en la biopiratería de la Estevia. A continuación le sigue Monsanto, acusado de biopiratería y con una larga historia de controversias con la producción de pesticidas y OGM:

Opposition to Monsanto bio-piracy patent on soybeans rejected | no patents on seeds http://no-patentson-seeds.org/en/information

@GeneticLiteracy and @ACSHorg are part of "Monsanto's networks," according to excellent @lemondefr graphic http://lemde.fr/2rojUYV

El primer tweet cita un artículo de la organización activista NO PATENTS ON SEEDS, donde entre otras encontramos que PublicEye (mencionada entre los protectores en la fig. 7 y los manifestantes fig. 6) forma parte de la organización. El artículo al que se refiere el tweet menciona a las empresas BASF, Bayer- 
Monsanto, DowDupont y Syngenta quienes estarían involucradas en la búsqueda de formas ilegales para patentar plantas y animales. En el tercer tweet se encuentra una infografía (muy interesante) publicada en el periódico francés Le monde[25] donde se identifica la red de instituciones que colaboran con Monsanto y como se encuentran relacionadas entre ellas: propaganda, abogados, lobbys, científicos, editoriales y blogs. El gráfico muestra las estrategias de Monsanto para crear influencia y presión en organizaciones como la OMS, y al mismo tiempo crear un sistema de desinformación en la opinión publica respecto a sus productos.

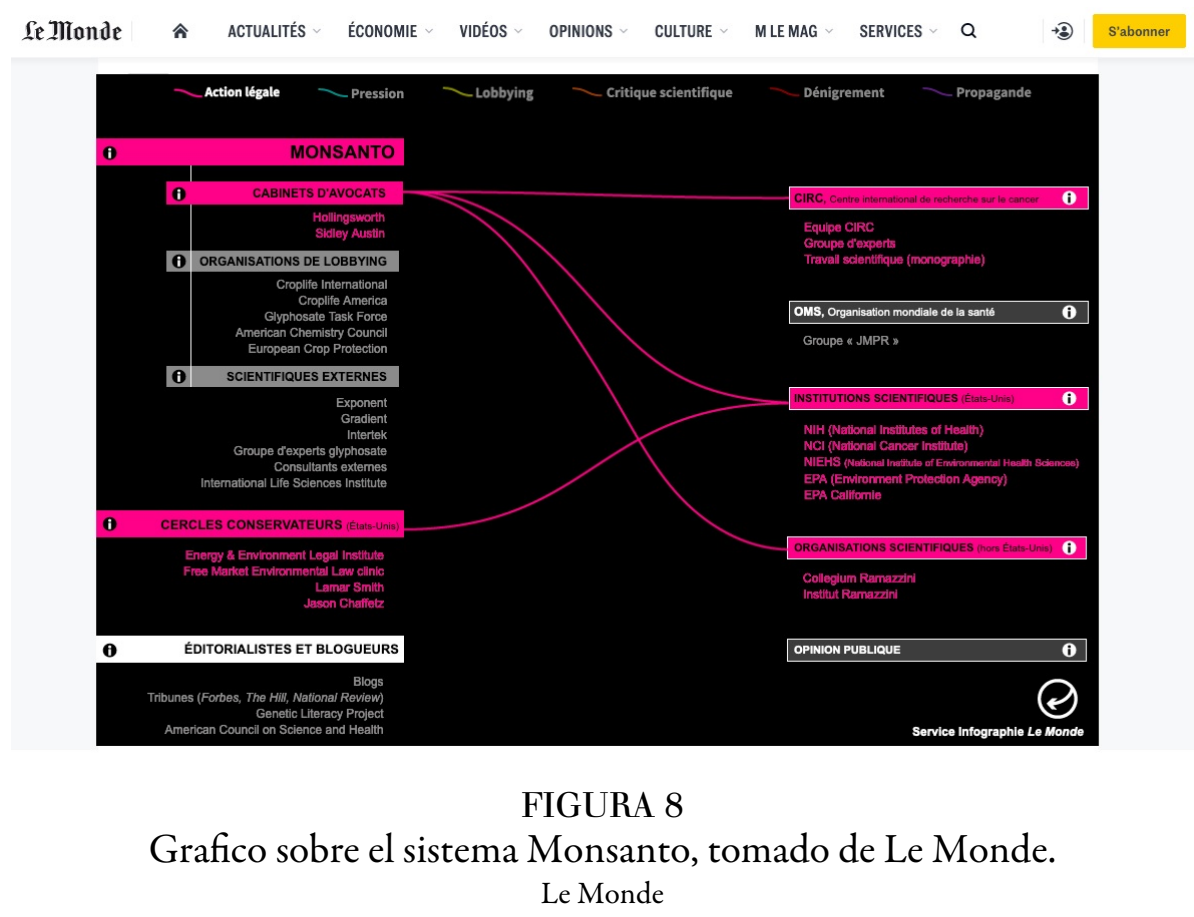

Por otro lado, en tercer lugar entre los depredadores encontramos a INVIMA (Instituto Nacional de Vigilancia de Medicamentos y Alimentos) [26], que es una institución del gobierno de Colombia encargada de gestionar las normas sanitarias relacionadas con los alimentos y medicinas. El tweet que se encontró es el siguiente:

Las declaraciones del Director del INVIMA, son anuncio de la legalización de la biopiratería. https:// opinadavid.wordpress.com/2017/07/05/sin-lanzar-mentiras-se-ve-mas-bonito/ @MartinJelsmaTNI

En el tweet se hace referencia a que INVIMA le negó el registro sanitario (en ese momento) a la organización Coca Nasa, quienes como productores de hoja de coca buscaban comercializarla creando una serie de productos. Mas tarde la organización obtuvo el registro y comercializa la hoja de coca[27].

Entre otros depredadores, se encuentran también DivSeek, el IRD y Nestle (involucrado en el caso Estevia) quienes ya los mencionamos anteriormente. Pero Nestle es también involucrado en el caso de la biopiratería de Rooibos.

A Nestle subsidiary is filing for patents on Rooibos derivatives in violation of South African law and the... http://fb.me/1sZm4mFjN

El tweet cita un artículo publicado en el site de la organización PublicEye, en el que se menciona que la filial de Nestle llamada Nestec, ha intentado registrar algunas patentes relacionadas con el Rooibos y sus propiedades para tratar enfermedades en la piel, sin respetar las reglas que propone el protocolo de Nagoya.

Por otro lado, se puede observar en la cartografía el termino "farmacéuticas", que se encontró en algunos tweets y donde se cita un artículo publicado en la Universidad de Miami (EEUU), el cual tiene como tema a la biopiratería de la medicinas tradicionales en el contexto legal[28]. Se identificó también a Bill Gates, fundador de Microsoft, quien es acusado de biopiratería, y en ciertos tweets mencionado junto a Monsanto. 
Biopiracy From Neem to Rice to Atta! Gates and Monsanto Influence IPR Policy https:// t.co/0UvxKKaxA1

NoGMOsVerified: Why is Bill Gates backing GMO red banana "biopiracy"? \#GMOs \#RightToKnow \#GMO /gw https://t.co/VX7FwnUTaj

En el primer tweet se cita un artículo de Vandana Shiva publicado en el sitio Internet de origen indio The Citizen[29]. En el texto, la activista explica como Monsanto y personajes como Bill Gates han intentado presionar a instituciones indias para modificar las leyes sobre la propiedad intelectual y adaptarlas a sus intereses particulares, principalmente centrados en la producción e introducción de productos y semillas OGM en la India. A la fundación Gates se le acusa de financiar DivSeek con el objetivo de controlar las patentes, los conocimientos tradicionales y científicos alrededor del registro de secuencias genéticas de plantas y semillas, creando bases de datos y bancos de semillas. En el otro tweet, se cita una publicación de la organización GMWATCH, donde se acusa a la fundación Gates de financiar el desarrollo de una variedad de plátano (OGM) con altos nutrientes, basado en genes robados de una variedad de plátano llamado Micronesian banana cultivar.

Entre los últimos depredadores mencionados se encuentra la dupla Merck-INBio. El tweet que se encuentra es el siguiente:

The practice- bioprospecting or biopiracy? - Bioprospecting initiatives such as the Merck- INBio deal are gaining ... https://t.co/4LO6sHJCYA

En este tweet se cita el libro Life industry: Biodiversity, People and Profits[30] donde se evoca el acuerdo al que llegaron el Instituto Nacional de Biodiversidad (INBio) en Costa Rica y la empresa farmacéutica Merck \& Co. El objetivo de este acuerdo fue desarrollar un proyecto de bioprospección en la región, regido sobre los principios del protocolo de Nagoya, es decir, el acceso a recursos genéticos y la participación de los beneficios.

Entrando totalmente con la cartografía de los protectores, encontramos que muchos de ellos ya los hemos mencionado, como a France Libertés, PublicEye y Vandana Shiva (entre otros), pero también se observa que en los territorios de America Latina, a un lado de los grandes territorios que ocupa Nagoya se encuentra el IEPI (Instituto de Ecuatoriano de la Propiedad Intelectual). A quien principalmente lo encontramos en tweets que mencionan las aportaciones del protocolo de Nagoya para combatir la biopiratería.

El \#ProtocolodeNagoya, una iniciativa internacional para combatir la biopiratería. \#IEPIAporta: http:// bit.ly/2uaDACr

RT @IEPI_Ecuador: El \#IEPI plantea lucha contra la \#Biopiratería, gracias a la implementación del \#ProtocoloNagoya \#PromesasCumplidas@cviterigualinga

Muchos de los tweets tienen que ver con la campaña lanzada por el gobierno ecuatoriano para celebrar la iniciativa del protocolo de Nagoya en la región como una herramienta para controlar la biopiratería. Se observa a un lado de IEPI al activista Carlos Viteri, quien también celebra el impacto del protocolo de Nagoya para controlar la biopiratería. En el contexto de Ecuador, también se encuentra que el presidente de Ecuador en ese momento, Rafael Correa también es citado en twitter por una conferencia en la Universidad Nacional de Ecuador y donde menciona el código Ingenios[31] y la prevención de la biopiratería.

Por otro lado, también se encuentra Indecopi (Instituto Nacional de Defensa de la Competencia y de la Protección de la Propiedad Intelectual) quien es la instancia en Perú encargada de proteger los conocimientos tradicionales y las plantas tradicionales de la región.

Perú: Según Indecopi, Sacha inchi, tara, aguaje y huanarpo macho en peligro por biopiratería. http:// bit.ly/2uNMT9O

En el tweet se cita un artículo del periódico La República de Perú, que lleva por titulo "Indecopi presenta oposición a una patente solicitada en China para el sacha inchi”. En el texto se menciona la lucha de las instituciones peruanas en su lucha contra la biopiratería de diversas plantas medicinales. En otro contexto, se observa TKDL[32] (Traditional Knowledge Digital Library), que es una base de datos desarrollada por 
el gobierno de la India para luchar contra la biopiratería y asimismo controlar sus recursos naturales y conocimientos tradicionales relacionados con la medicina ayurvédica.

Por otro lado, se identificaron algunos tweets que citan a una empresa llamada Aïny[33]. El tweet menciona un artículo de InfoGM, que lleva por título Aïny, une entreprise qui lutte contre la biopiraterie[34]. En el texto se explica de manera resumida la historia de la empresa, la cual tiene el objetivo de construir una alternativa contra la biopiratería, desarrollando un comercio justo basado en el bien común. Por último, se observa a LAEC (L'Avenir en Commun), que se refiere al programa del partido político francés France insoumise[35]. El tweet cita el programa donde se menciona "la urgencia ecológica de salvar el ecosistema y la biodiversidad". En esa sección del programa se hace referencia a rechazar el registro de patentes relacionadas con seres vivos y la biodiversidad, y asimismo luchar contra la biopiratería.

\subsection{Los territorios de las medicinas tradicionales}

A continuación se presenta la cartografía de las plantas medicinales y otras substancias encontradas en los tweets. La cartografía se desarrolló analizando las bases de datos, e identificando las plantas y otras substancias en los textos de los tweets.

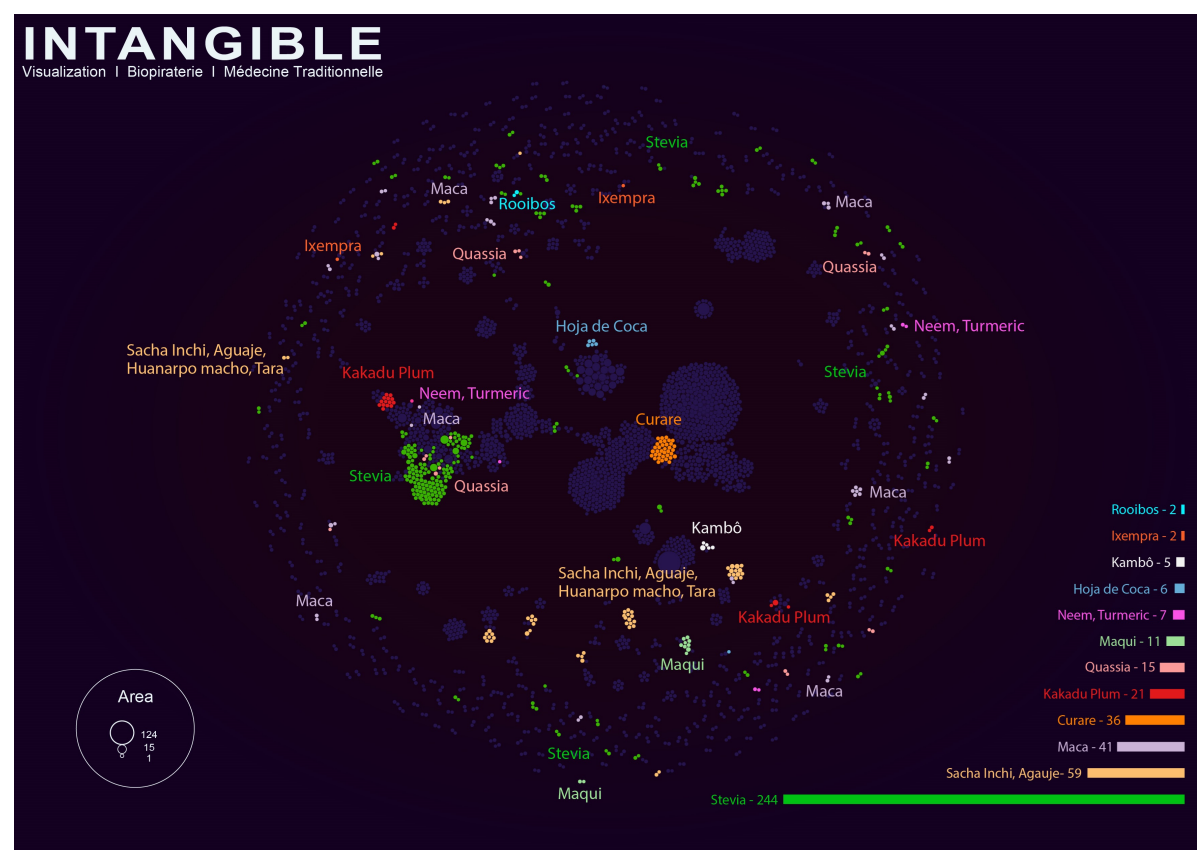

FIGURA 9

Cartografía de las plantas medicinas

autores

Observamos en la cartografía las menciones de diversas plantas, una substancia obtenida de una mezcla de plantas (Curare), la secreción que se extrae de la rana Phylomedusa bicolor (Kambô) y una bacteria descubierta en Africa del Sur (Ixempra). Por tanto, se conoce que la Stevia, la Sacha Inchi, el Aguaje, el Huanarpo macho, la Tara, la Maca, el Curare, la Quassia, el Maqui, la Hoja de coca y el Kambô son de origen latinoamericano. También se observa el Kakadu plum de origen australiano, y el Neem y el Turmeric de origen indio, y entre los menos mencionados la Ixempra y el Rooibos de origen africano. Entre todos ellos la Ixempra no se encuentra su uso en las medicinas tradicionales, pero se menciona como un caso de biopiratería.

En el territorio francés, que es donde hay mayor movimiento de manifestantes involucrados, se encuentra el caso de la Estevia y la coca-cola. Asimismo la Quassia Amara también se encuentra en el mismo territorio que la Estevia y comparte algunos activistas que se encontraron mencionados en los tweets, como France 
Libertés (esos dos casos ya los mencionamos en el apartado de manifestantes). En la misma región y en la periferia se observa el Kakadu Plum que es mencionada en dos tweets:

Bio-piracy: US companies patenting extract from the Kakadu plum I The Feed https://t.co/ NxDD27AX3M ProteinWorld secret deal page.

Protecting the Kakadu in Kakadu plums Income for Indigenous Australian communities - with protection... https://t.co/haVqPrsq1A

El primer tweet cita un video publicado en Youtube en el canal The Feed SBS, que forma parte de la empresa australiana de medias SBS[36], el cual hace un resumen de la la historia del uso del Kakadu Plum como medicina tradicional entre las comunidades aborígenes de Australia. Se mencionan también las propiedades del árbol y sus potenciales usos para tratar el Alzheimer, el cáncer y la diabetes. Sobre la biopiratería se cita el caso de Mary Kay, la empresa de cosméticos, la cual ha registrado diversas patentes y desarrollado diversos productos a partir del extracto de Kakadu Plum, sin respetar el protocolo de Nagoya. Al mismo tiempo se cita el caso de biopiratería de Monsanto en la India. En el segundo tweet, se cita un artículo publicado en el periódico The Guardian[37], donde se menciona la riqueza del Kakadu Plum en vitamina C y el ya citado caso de Mary Kay. Asimismo, como una estrategia para empoderar a las comunidades, se cita el proyecto First Australians Capital[38], el cual tiene como objetivo financiar a emprendedores aborígenes.

En el mismo territorio francés y la periferia también se encuentra la Maca, que se observa en tercer lugar en cuanto a menciones. La Maca es una raíz de origen peruano, la cual tiene una historia que nos lleva hasta los Incas y la prehistoria. Algunos de los tweets que identificamos son los siguientes:

Les voleurs de \#maca, film \#pérou https://t.co/5P1rHw2KsD \#biopiraterie @Francelibertes @IndecopiOficial@ARTEfr

Biopiratería en China contra el Perú ? Advierten que China intenta patentar la maca como suya http:// larepublica.pe/sociedad/89218

Peru's Maca Biopiracy Problem - VICE News Tonight - VICE Video https://t.co/hD1HcBSC28

El primer tweet evoca algunos de los actores mencionados como protectores y manifestantes, como Indecopi y France Libertés. El tweet cita un artículo publicado en el sitio de la organización InfoGM y el cual hace un resumen del documental Les voleurs de maca, que cuenta la historia de la biopiratería de la Maca. Según el resumen, el documental hace mención a la biopiratería de la Maca por parte de empresas chinas, quienes lograron sacar ilegalmente de Perú muestras de Maca para cultivar y producir ellos mismos el tubérculo en China. Como consecuencia, se menciona que empresas chinas han registrado más de 10 patentes y producen 3 veces más Maca que Perú sin ningún respeto a los tratados internacionales. Asimismo, se cuenta que la empresa estadounidense Pure World Botanicals registro una patente para monopolizar el uso de la Maca en el país. En contraparte, el documental también relata como las instituciones peruanas como Indecopi luchan contra la biopiratería. El gobierno de Perú creo una instancia dentro de Indecopi llamada Comisión Nacional contra la Biopiratería[39], la cual esta encargada de proteger la biodiversidad y los conocimientos tradicionales de la biopiratería.

En concordancia con el primer tweet, el segundo cita un artículo del sitio del periódico peruano La República[40], que se refiere a la biopiratería de la Maca por parte de empresas chinas y como intentan apropiarse de la raiz. El tercer tweet cita un video producido y publicado por ViceNews[41], en el cual se relata la problemática de la biopiratería de la Maca. En el video se observan testimonios cortos de algunos campesinos peruanos y también se menciona el complicado trabajo que realizan las instituciones peruanas para proteger la Maca en el marco legal del registro de patentes y del protocolo de Nagoya.

Continuando en el análisis del territorio francés, se observan asimismo el Neem y el Turmeric, dos plantas muy comunes en la medicina ayurvédica de origen indio que son mencionadas en una conversación en Twitter:

\#hortusmalabaricus, based on itty achuthan's vaidya family's palmleaf manuscripts and written by him and three konkan bhats...1/2 
was written around $1595 \mathrm{CE}$ in latin and is a great compendium of \#priorart preventing massive \#biopiracy eg in turmeric, neem etc. $2 / 3$

so that anyone claiming \#patents on medical uses of indian plants, as they do often in the west, will find their patents invalidated.

En la conversación se cita al manuscrito Hortus malabaricus [42], según el tweet publicado en 1595 (según wikipedia entre 1678-1693), en el cual se hace una clasificación y una descripción de las plantas medicinales en la India. Al mismo tiempo se menciona el tratado como una fuente importante en la lucha contra la biopiratería.

Cambiando de territorio, si observamos hacia la America Latina, podemos identificar al Curare, la substancia mezcla de plantas y utilizada por los indios Jivaros de la amazonia.

\#Biopirateria en 1839 Gill et.al se llevó 25 kilos de curare a USA! Hoy Ecuador gasta 600k usd al año en Rocuronio...

En el tweet se menciona un fragmento de una historia del Curare. Buscando en Internet alguna información al respecto, se encontró en wikipedia y otras fuentes [43] la historia a la cual se refiere el tweet, con ciertas diferencias, ya que Richard Gill vivió entre 1901-1958. Asimismo, fue hacia 1938 cuando Richard Gill extrajo de la amazonia ecuatoriana 25 libras de Curare para transportarlas a EEUU. Este tweet nos permite reconstruir de cierta forma, una historia de bioprospección.

En otros tweets en el mismo contexto, se observan algunos tweets acerca de diferentes plantas medicinales de origen peruano, el Sacha inchi, tara, aguaje y huanarpo macho. El principal tweet se refiere a un artículo publicado en el periódico La República (el artículo lo podemos encontrar en AgroForum[44]) y donde se menciona el peligro por biopiratería. Entre los países involucrados en la biopiratería de las plantas citadas, más la Maca, se encuentran China, Corea, Japón, Taiwan, Hong Kong y Filipinas y Francia. Por otro lado, sobre le Maqui, es posible identificar algunos tweets en la periferia, los cuales se refieren a una situación de biopiratería tanto local como internacional.

El maqui bajo amenaza de biopiratería por universidades chilenas y empresas internacionales | Mapuexpress https://t.co/RB53imuoaa

El Maqui es el fruto de un árbol, que se usa por sus propiedades medicinales en la cultura Mapuche, desde la época prehispánica. El tweet, menciona un articulo del sitio Internet del Colectivo de Comunicación Mapuche Mapuexpress[45], la cual es una organización activista que lucha por los derechos de la comunidad Mapuche. En el artículo se menciona la biopiratería del Maqui, por un lado, por parte de universidades chilenas y por otro lado empresas estadounidenses, quienes no respetan los tratados nacionales e internacionales, como el protocolo de Nagoya, la Declaración de la ONU sobre los Derechos de los Pueblos Indígenas y la Ley Indígena promulgada por el gobierno chileno en 1993. El caso del Maqui es interesante ya que la problemática de la biopiratería no solo es internacional entre países, sino también en una problemática local, cuando en un mismo país no se reconocen, valoran y protegen los conocimientos tradicionales locales. Siguiendo en el contexto de America Latina, se observa el Kambô, la secreción de la rana Phylomedusa bicolor, de origen amazónica (Brasil), se dice en el tweet que también ha sido objeto de biopiratería por parte de farmacéuticas, pero no se cita ninguna fuente. Pero de alguna forma, el tweet nos permite buscar información al respecto y conocer el contexto del Kambô. Otro caso que se observa en el mismo contexto, es el de la hoja de coca y la controversia con INVIMA que ya mencionamos anteriormente, en el capitulo sobre los depredadores.

Por otro lado, en el contexto de Africa se observan la Ixembra y el Rooibos. La Ixembra, que como dijimos antes es una bacteria que fue encontrada en Africa del Sur y se identificó en el siguiente tweet:

At \#OpenGlobalSouth @margobagley: giving examples of ethnobiological research and biopiracy - e.g., Ixempra from South African soil microbe

El tweet como se observa, no menciona alguna fuenta en particular, solo cita a Margo Bagley[46], quien se encuentra que es una investigadora en leyes de la Universidad Emory en EEUU, interesada en los aspectos 
legales sobre la biotecnología, los recursos genéticos y los conocimientos tradicionales, en el contexto del protocolo de Nagoya. Finalmente, el otro caso africano, es el Rooibos, el cual es un arbusto que tiene su origen en Africa del Sur, y se menciona que tiene propiedades antioxidantes y por tal motivo en riesgo de biopiratería. El caso del Roiboos se encuentra relacionado con la empresa Nestle, la cual es acusada de biopiratería, como lo mencionamos en el análisis de los depredadores.

\section{Conclusiones}

En este artículo se presentó una investigación cualitativa y cuantitativa donde se propone un método de investigación basado en los llamados métodos digitales utilizando herramientas abiertas (open source). La investigación nos permite conocer el contexto de la situación de la biopiratería utilizando una muestra de datos de un momento específico.

La cartografía y la visualización de datos nos permite observar el contexto de interacción y participación en Twitter. Se identifican en los textos las diferentes entidades y se clasifican según los roles que juegan en el contexto de la biopiratería. En el proceso del diseño visual, se interpreta cada entidad de manera cualitativa y cuantitativa con el objetivo de hacerlos visibles. El carácter global y abierto de Twitter nos permitió identificar a los principales manifestantes en un momento específico. La cartografía presentada es en sí misma una interpretación y por lo tanto es una visión particular de la biopiratería. Por tanto, mediante los métodos digitales fue posible construir un discurso de análisis y visualización para interpretar el fenómeno de la biopiratería de las medicinas tradicionales a partir de las publicaciones de los usuarios.

Twitter es una red social abierta en la cual los usuarios participan libremente, por lo que en un intento de respeto a la privacidad, se decidió que en el diseño visual de la cartografía, no mostrar los nombres de los usuarios para mantener el respeto a su privacidad.

A partir de los resultados podemos decir que la biopiratería es una problemática que principalmente afecta a los países donde existe una biodiversidad importante. Al mismo tiempo, la implementación del protocolo de Nagoya se encuentra que es complejo por las características de actores que participan y las propiedades de cada región y país. Los altos niveles de corrupción no ayudan tampoco para crear confianza en las comunidades y las organizaciones para implementar proyectos de bioprospección, aunque existan ciertas leyes aprobadas.

Las propuestas de gestión de datos sobre genes y semillas concentrando toda esa información en una sola entidad, que tiene relación con otras entidades las cuales tienen intensiones que no tienen que ver con el desarrollo del ser humano y la biodiversidad es un riesgo para todos los seres vivos y el planeta. Al final el poder y el dinero ponen en riesgo las buenas ideas.

En términos de la propiedad privada, se propone el uso la propiedad abierta y compartida para el bien común (commons), que sea adaptable a cada región, comunidad y país, respetando los derechos de cada comunidad a gestionar sus propios conocimientos y la biodiversidad relacionada.

Este estudio exploratorio nos permite tener una base de conocimientos y una metodología para seguir una investigación más específica sobre cada una de las plantas medicinales identificadas en Twitter.

\section{REFERENCIAS}

Aubertin, C., \& Moretti, C. (2013). La biopiraterie, entre illégalité et illégitimité. In: Les Marchés de la Biodiversité (p. 269). Institut de recherche pour le développement.

Aubertin, C., Pinton, F., \& Boisvert, V. (2007). Les marchés de la biodiversité. In: Recherche (IRD Editio). Paris: Institut de Recherche pour le Développement.

Borra, E., \& Rieder, B. (2014). Programmed method: developing a toolset for capturing and analyzing tweets. Aslib Journal of Information Management, 66(3), 262-278. https://doi.org/10.1108/AJIM-09-2013-0094 
Boumediene, S. (2016). La colonisation du savoir: une histoire des plantes me\#dicinales du "Nouveau Monde" (1492-1750). Vaulx-en-Velin: Les e\#ditions des mondes a\# faire.

Burelli, T. (2004). Le Patrimoine Ethno-Environnemental: Nouveau Paradigme pour la définition des Droits Intellectuels Autochtones. Presses Universitaires de La Nouvelle-Calédonie, 87-117.

CBD. (2012). Protocole de Nagoya sur l'accès aux ressources génétiques et le partage juste et équitable des avantages découlant de leur utilisation relatif à la Convention sur la diversité biologique. Convention Sur La Diversité Biologique Nations Unies, p. 26. http://www.cbd.int/abs/doc/protocol/nagoya-protocol-fr.pdf

Delgado, G. C. (2002). Biopi acy and Intellectual Property as the Basis for Biotechnological Development: The Case of Mexico. International Journal of Politics, Culture and Society, 16(2), 297-318.

Diminescu, D. (2012). Introduction: Digital Methods for the Exploration, Analysis and Mapping of e-Diasporas. Social Science Information, 51(4), 451-458. https://doi.org/10.1177/0539018412456918

Dumesnil, C. (2012). Les savoirs traditionnels médicinaux pillés par le droit des brevets\#? Revue Internationale de Droit Économique, XXVI(3), 321-343. https://doi.org/10.3917/ride.257.0321

Galinon-Me\#le\#nec, B., \& Zlitni, S. (2013). Traces nume\#riques: de la production a\# l'interpre\#tation. (C. E\#ditions, Ed.). : Paris.

IEPI. (2016). Primer informe sobre biopiratería en el ecuador. Quito.

RAFI. (1994). COPs... and Robbers...Transfer-Sourcing Indigenous Knowledge. Pirating Medicinal Plants. Occasional Paper Series, 1(4), 20. Retrieved from http://www.etcgroup.org/content/volume-1-4-piratingmedicinal-plants

Rieder, B. (2013). Studying Facebook via Data Extraction: The Netvizz Application. Proceedings of WebSci '13, the 5th Annual ACM Web Science Conference, 346-355. https://doi.org/10.1145/2464464.2464475

Rogers, R. (2013). Digital Methods. Massachusetts: MIT Press.

Rogers, R. (2019). Doing Digital Methods. London: Sage Publications, Ltd.

Severo, M., \& Romele, A. (2015). Traces numériques et territoires. Paris: Presses des Mines.

Severo, M., \& Venturini, T. (2015). Intangible cultural heritage webs\#: Comparing national networks with digital methods. New Media and Society, 18(8), 1616-1635. https://doi.org/10.1177/1461444814567981

Severo, M., \& Venturini, T. (2016). Enjeux topologiques et topographiques de la cartographie du web. Reseaux, 1(195), 85-105. https://doi.org/10.3917/res.195.0085

Shiva, V. (1997). Biopiracy: the plunder of nature and knowledge. Ontario: Between the lines.

UNESCO. (2003). Convention pour la Sauvegarde du Patrimoine Culturel Immateriel (p. 14). Paris.

\section{Notas}

[1] http://www.wipo.int/meetings/en/details.jsp?meeting_id=42302

[2]https://absch.cbd.int/es/

[3]https://ich.unesco.org/es/RL/la-cosmovision-andina-de-los-kallawayas-00048

[4]https://wiki.digitalmethods.net/Dmi/ToolDmiTcat

[5]https://tags.hawksey.info/

[6]http://openrefine.org/

[7]Sobre el término trace y trace numérique existe en Francia un interés particular. Se mencionan como variantes : trace d'activité, traces de navigation, traces interactives, traces de visite, traces explicites et implicites. Asimismo se encuentra el término traçabilite. Ver Bastard, Cardon, Charbey, Cointet, \& Prieur (2017), Severo \& Romele (2015), y el libro Traces numériques (GalinonMe\#le\#nec \& Zlitni, 2013).

[8]https://gephi.org/ 
[9]https://www.telesurenglish.net/news/Mexicans-Protest-Law-That-Will-Amount-to-Biopiracy-for-IndigenousCommunities-20170413-0006.html

[10]http://www.humanite.fr/biopiraterie-les-guarani-reclament-les-fruits-de-la-stevia-coca-637471

[11]https://larepublica.pe/economia/1074508-indecopi-presenta-oposicion-a-una-patente-solicitada-en-china-para-el-sachainchi/

[12]https://www.publiceye.ch/en/media-corner/press-releases/detail/stevia-260000-signatures-demanding-from-coca-cola-tostop-its-biopiracy

[13]https://www.publiceye.ch/en/topics/biopiracy/case-studies/stevia

[14]https://blogs.mediapart.fr/francelibertes/blog/290517/cas-de-biopiraterie-quassia-amara-la-defense-laborieuse-de-l-ird? utm_source=twitter\&utm_medium $=$ social\&utm_campaign $=$ Sharing\&xtor $=$ CS3-67

[15]https://www.infogm.org/6135-pourquoi-recherche-publique-accusee-biopiraterie?lang=fr

[16]https://www.infogm.org/6278-divseek-chronique-biopiraterie-legalisee?lang=fr

[17]https://divseekintl.org/

[18]https://viacampesina.org/es/

[19]https://ccfd-terresolidaire.org/

[20]http://etcgroup.org/content/captain-hook-awards-reveal-biopirate-villains-and-celebrate-biodiversity-defenders-un

[21]https://www.facebook.com/ConsejoMayaBacalar/

[22] https://www.tppmexico.org/

[23]https://www.reuters.com/article/agricultura-mexico-glifosato-idLTAKBN2AJ2BN

[24]https://www.seedthemovie.com/

[25]https://www.lemonde.fr/planete/visuel/2017/06/01/operation-intoxication-les-reseaux-demonsanto_5136945_3244.html

[26]https://www.invima.gov.co/

[27]https://www.cocanasa.org/

[28]https://repository.law.miami.edu/umblr/vol23/iss3/5/

[29]https://www.thecitizen.in/index.php/en/NewsDetail/index/1/7840/Biopiracy-From-Neem-to-Rice-to-Atta-Gates-andMonsanto-Influence-IPR-Policy

[30]http://www.nzdl.org/cgi-bin/library?e=d-00000-00---off-0envl--00-0----0-10-0---0---0direct-10---4-------0-11--11en-50---20-about---00-0-1-00-0-0-11-1-0utfZz-8-00\&cl=CL1.4\&d=HASH01230cb240ad6e29c7cc9d20.5>=1

[31]https://www.derechosintelectuales.gob.ec/el-codigo-ingenios-una-legislacion-equitativa/

[32]http://www.tkdl.res.in/tkdl/langdefault/common/Home.asp?GL=Eng

[33]https://www.ainy.fr/

[34]https://www.infogm.org/6156-ainy-entreprise-lutte-contre-biopiraterie?lang=fr

[35]https://laec.fr/section/45/sauver-1-ecosysteme-et-la-biodiversite\#mesure-2

[36]https://www.sbs.com.au/

[37]https://www.theguardian.com/sustainable-business/2017/may/26/protecting-the-kakadu-in-kakadu-plums-selling-bushfoods-to-the-world 
Luis Torres-Yepez, et al. Protectores VS Depredadores. Cartografía y visualización de la biopirate...

[38]https://firstaustralianscapital.org/

[39]https://www.indecopi.gob.pe/web/biopirateria

[40]https://larepublica.pe/sociedad/892186-advierten-que-china-intenta-patentar-la-maca-como-suya/?ref=lre

[41]https://www.youtube.com/watch?v=kmXoQN9SUaY

[42]https://archive.org/details/HortusMalabaricus

[43]https://pubs.asahq.org/anesthesiology/article/57/6/519/27898/The-Gill-Merrill-ExpeditionPenultimate-Chapter-in [44]https://www.agroforum.pe/agro-noticias/sacha-inchi-tara-aguaje-y-huanarpo-macho-peligro-biopirateria-11838/

[45]https://www.mapuexpress.org/2016/08/19/el-maqui-bajo-amenaza-de-biopirateria-por-universidades-chilenas-yempresas-internacionales/

[46]https://www.researchgate.net/profile/Margo-Bagley 